\title{
In-service teacher attitudes toward the use of the mother tongue in Norwegian EFL classrooms
}

Georgios Neokleous

Ingunn Ofte

Norwegian University of Science \& Technology

georgios.neokleous@ntnu.no ingunn.ofte@ntnu.no

\begin{abstract}
Despite the increasing emphasis on a bilingual approach to EFL teaching that embraces the use of the mother tongue (MT), recent research reports that national curricula around the globe still suggest maximal use of the target language (TL) (García \& Wei, 2014; May, 2014; Shin, Dixon, \& Choi, 2020). Consequently, EFL teachers often assume that students prefer an environment that makes little to no use of their MT (Flores \& Aneja, 2017; Hall \& Cook, 2012). In an attempt to unravel how this shift away from a separation of languages to what has been labelled a "multilingual turn" (May, 2014, p.2) is perceived among in-service teachers, this study brings together classroom and interview data from four EFL classrooms in Norway. Observing four teachers in primary and lower secondary schools, the study attempts to unravel teacher attitudes towards MT use. Trying to examine whether their stated behaviour corresponds to their classroom realities, the study also asks participants to selfreport on their MT usage. Additionally, the article explores whether the lack of clear guidance in the English subject curriculum regarding MT applications may add to the confusion as to how, when, and if it should be used. The results suggest that despite acknowledging the potential of the MT, the four participants also felt guilty about its presence, particularly since their reported use did not always reflect their classroom behaviours. In light of these findings, the paper suggests future research including young and adult EFL learners be conducted in order to analyse judicious MT use in the English language classroom.
\end{abstract}

Keywords: Mother Tongue, Teacher Attitudes, Teacher Self-reporting, EFL Classrooms 


\section{Introduction}

Since the mid-1980s, the use of the mother tongue (MT), or the majority language of a country, in EFL classrooms was frowned upon and advised against, as it was assumed to hinder target language (TL) proficiency (Hall \& Cook, 2012; Shin, Dixon, \& Choi, 2020). Consequently, the English-only approach became synonymous with optimizing learning. Current scholarship promulgates judicious or optimal MT use to advance EFL students' reading and writing skills. However, few studies have attempted to shed light on what the term judicious means in practice (Lin \& Wu, 2015; Lee \& Levine, 2018; Neokleous, 2017; Neokleous \& Krulatz, 2018). As it is unclear how much MT use could be considered judicious in monolingual environments, EFL teachers are often left wondering when they should or not integrate the MT in the classroom.

Deciding on appropriate MT use has been one of the greatest challenges EFL teachers face in linguistically homogeneous classrooms. Traditionally, Norwegian classrooms in primary education have been monolingual, as students and teachers share the same MT (Surkalovic, 2014). While the English subject curriculum presupposes that the MT does have a place in the classroom as it states that students should be able to identify linguistic similarities and differences between the two languages, it says little about the classroom purposes it should serve (Norwegian Directorate for Education \& Training, 2020). A lack of clear instructions could lead teachers to resort to the approach that has been for years perceived as ideal for language learning: namely, promoting a setting which makes exclusive use of the TL (Neokleous \& Krulatz, 2018). However, research has also shown that imposing an all-English policy and restricting any references to the MT could make students adopt a negative attitude towards the TL (Burden, 2000; Liu \& Jackson, 2008).

In Norway, English has developed a special status which oscillates between EFL and ESL (Simensen, 2005). Traditionally, the teaching of languages other than Norwegian has been perceived as foreign language teaching. While the influence of English is prevalent outside the classroom, it cannot be understood as a second language as it is not the main language spoken and it does not have an official status in Norwegian society. Simensen (2005), however, argued that English is learned to some extent as a second MT, which is in stark contrast to the ways in which the other foreign languages are taught. The purpose of this 
study was to reveal the attitudes of in-service EFL teachers in Norway regarding MT use in EFL settings.

Thus far, studies exploring MT use in Norwegian EFL settings have focused on eliciting the teacher voice through questionnaires (Krulatz, Neokleous, \& Henningsen, 2016; Neokleous \& Krulatz, 2018). This is the first study in Norwegian EFL learning environments that brings classroom and interview data together to unravel how in-service teachers perceive MT integration and compare this perception to their actual practice. The study also examines how the participants interpret the lack of clear teaching guidelines in the curriculum (Norwegian Directorate for Education and Training, 2020) regarding the ideal amount of TL and MT to be used in the EFL classroom, and the purposes they believe each language should serve.

\section{Literature Review}

Surveying the growing literature on MT use in the EFL classroom, Hall \& Cook's (2012) state-of-the-art article revealed that globally, for a considerable number of years, the consensus was that the ideal learning environment for beginners was the one that made exclusive use of the TL (Hall \& Cook, 2012; Makalela, 2015; McMillan \& Rivers, 2011). The origin of this belief has been attributed to the waning of the grammar-translation method and the rise in popularity of Krashen's (1985) input hypothesis (Hall \& Cook, 2012; Wang, 2019). On the one hand, the grammar-translation method, which heavily relied on the use of the MT as it required students to translate sentences between the MT and the TL, was no longer believed to have a positive impact on students' mastery of English. On the other hand, Krashen's monitor model postulated that language input was crucial in the development of students' TL fluency, and therefore, teachers should provide an environment that promoted exclusive use of the TL (Chambers, 1991; MacDonald, 1993). The emergence of new teaching methodologies, such as Communicative Language Teaching (CLT) and the Direct Method, both of which also advocated extensive use of the TL, further cemented the idea of an all-English environment as the ideal language learning setting (May, 2014). To abide by the model setting principle, Inbar-Lourie (2010) argued that "language teaching pedagogy has tended to ignore or...suppress bilingual or multilingual options endorsing a predominantly 
monolingual policy, one which equates 'good teaching' with exclusive or nearly exclusive target language use" (p. 351). As a result, MT use has often been perceived by EFL teachers as a source of embarrassment and even, in some cases, incorrect teaching practice (Aronin \& Singleton, 2019; Shin, Dixon, \& Choi, 2020).

Through the integration of new approaches to EFL teacher training programmes, an English-only approach was enforced by national curricula for foreign language teaching across the globe ((Hall \& Cook, 2012; McMillan \& Rivers, 2011; Sampson, 2012). While English subject curricula in some countries, including, for example, Hong Kong and South Korea, prescribed exclusive use of the TL (The Curriculum Development Council, 2004; Kim, 2008), other curricula in other countries imply TL-dominant instruction through the integration of the aforementioned methodologies. The main argument in favour of the allEnglish approach relied on the idea that the classroom often constituted the only environment in which students were exposed to EFL, and teachers should thus ensure as much input as possible to develop students' language skills.

The growing perception that MT use impeded the development of students' English skills has culminated in the negligence of some of the important benefits associated with MT use (Brown, 2009; García \& Kleyn, 2016; Shin, Dixon, \& Choi, 2020; Turnbull, 2001; Wang, 2019). Contrary to popular belief, research conducted over the past decade indicates that MT use in the classroom could positively affect the linguistic growth of EFL students (Cheng, 2013; Creese \& Blackledge, 2010; Halasa \& Al-Manaseer, 2012; Hall \& Cook, 2012; Lee \& Macaro, 2013; Lin \& Wu, 2015). Aside from the pragmatic impossibility of escaping the influence of the MT, arguments for its use in the classroom include that students could always rely on their MT to ask for clarification, that they could establish connections between their MT and the TL, and that the MT could provide a sense of security to the students (Mattioli, 2004; Tarnopolsky, 2000). An explanation in the MT could eradicate ambiguities or sources of confusion by drawing students' attention to specific language points, while it could also save time and sustain motivation (Carless, 2008; Neokleous, 2017). Most significantly, however, MT use was believed to assist low-ability students in improving their TL knowledge, as recourse to their MT could provide additional cognitive support and help them follow along (Shin, Dixon, \& Choi, 2020). 
Yet, the idea of limiting MT use in the classroom to comply with the official guidelines, along with the difficulty of maintaining an all-English setting in monolingual EFL classrooms, generated feelings of guilt among teachers "for straying from the ... [TL] path" (Cook, 2001, p. 405). Because of teachers' practice of resorting to MT use as needed in their English lessons, EFL teachers experience feelings of self-reproach as they perceive the use of the MT in the classroom to be incorrect (Carless, 2008; Copland \& Neokleous, 2011). As a result, Copland and Neokleous (2011) maintain that "the teachers' professed desires about ... [MT] use are clearly in conflict with their classroom realities, leaving them feeling damned if they speak ... [in their MT] and damned if they do not" (p. 278). However, young learners have been shown both to have a positive attitude towards the use of the MT in the EFL classroom and to be acutely aware of the disadvantages of an all-English learning environment (Neokleous, 2017). Of note is that, in Neokleous's (2017) study, 68.4\% of EFL young learner respondents highlighted their preference of learning from instructors who share the same MT; a preference also shown in studies by Lee and Macaro (2013) and Lin and Wu (2015).

Recently, scholarly interest seems to have swung towards research stressing the role the MT could have as a catalyst to the learning experience, thus encouraging teachers to adopt a bilingual approach to teaching with the MT being actively present (Shin, Dixon, \& Choi, 2020). This has been identified in the literature as optimal or judicious MT use (Cheung \& Braine, 2007; Macaro, 2001). This concept, however, is rather elusive and it is unclear how it translates into usages in different classrooms at different grades. Bateman's (2008) study exploring the views of ten pre-service teachers about EFL classroom situations in which MT can best be utilized concluded that "the activities in which...[they] felt using the L1 was necessary were those that involved complications that arose during instruction, such as providing clarification when students didn't understand, providing individual help to struggling students, and addressing discipline problems" (pp. 17-18). These were the same reasons underpinning the choice by the participants in Macaro (2001) and Orland-Barak and Yinon (2005) for the L1 over the L2.

The potential for the balanced alternation between the MT and the TL to augment language acquisition in the EFL classroom was further strengthened by recent research investigating the concept of translanguaging (Creese \& Blackledge, 2010; García, 2009; 
García, Johnson, \& Seltzer, 2017; Otheguy, García, \& Reid, 2015). The practice of translanguaging acknowledges students' entire linguistic repertoire as a resource, and optimizes EFL pedagogy suggesting that the languages cannot be kept separate (García, 2009).

Research undertaken in Norwegian EFL settings illustrated that the MT was quite prevalent as the medium of instruction and was essentially used for translation purposes (Drew, 2004; Drew, Oostdam, \& van Toorenburg, 2007; Eikrem, 2012; Mehl, 2014).

Eliciting the views of 56 in-service teachers through surveys distributed to 96 schools across Norway, Krulatz, Neokleous, and Henningsen's (2016) study revealed that English was employed more frequently "for oral than for written communication with the students" (p. 144). In their self-reports, the teachers suggested that the TL was primarily used for praise and everyday conversation, while they seemed to share a penchant for using the MT when lecturing, giving instructions, and maintaining discipline (see also Macaro, 1997; OrlandBarak \& Yinon, 2005). However, Krulatz et al.'s (2016) study highlighted the lack of interviews and observations as one of the main limitations of research in this area, as other methods for gathering data could shed additional light on teacher's attitudes towards the MT, as well as their teaching practices. This was precisely the gap that this study attempted to close.

\section{Methodology}

The purpose of the present study was to obtain information about the way in-service teachers feel regarding the use of the MT in Norwegian EFL environments. The research questions the study attempted to address were:

1. What do Norwegian in-service EFL-teachers think of the use of the MT in the classroom?

2. When do teachers think the MT should be used? For what classroom purposes?

3. Do teachers' accounts of their MT use correspond to their classroom realities? 
4. Do Norwegian in-service EFL teachers believe that the English subject curriculum for the subject of English should provide clearer guidelines regarding the use of the MT in the classroom?

Data were collected through formal classroom observations and the use of semi-structured interviews. The participants were four in-service Norwegian teachers who had English included in their teacher education and who were working at three different state schools located in a Norwegian city. Three of the teachers were attending a further education course for in-service English teachers in grades 5-10 at the time of the study. The fourth teacher was a colleague of one of the teachers attending the in-service course. All four participants signed up voluntarily, and concession was granted from the administration of the three schools. Furthermore, pseudonyms were given to each teacher: Anita, Anne, Torill, and Berit. The participants were all females as no male EFL teachers in the three schools and the further education course volunteered to participate. Of the three participating schools, two were urban schools, while one was situated outside the metropolitan area. The four classes observed were single-grade classes for grades 7,8,9, and 10, and the average class size was 21 students per class. Anita taught the $7^{\text {th }}$ grade class, while Anne the $8^{\text {th }}$ grade class, Torill the $9^{\text {th }}$ grade class, and Berit the $10^{\text {th }}$ grade class. Henceforth, the digit in brackets next to the participants' pseudonyms indicates the grade they taught.

These four teachers and their classes provided the sample for this study. The paper acknowledges that this is a convenience sample and that it might not be representative of the teacher population of the city nor was it intended to be so. The two researchers, however, maintain that the findings provide insights that might potentially be applicable in different contexts. Interview and observation protocols were developed to contribute to the consistency of the data collected. The observation protocol was based on Neokleous' (2017) study. These protocols enabled the researchers to maintain a clear focus during the interviews and the onsite observations. The four classes were observed in three different periods throughout the spring semester of 2018, and at the end of the semester, the teachers of these classes were individually interviewed.

The observations assisted the researchers in giving a general overview of the purposes for which the teachers made recourse to the MT. The interviews enabled the 
participants to provide their perspectives on the study's topic. Semi-structured interviews were chosen because they allowed comparison while at the same time providing opportunities for queries that arose from the observation data or during the interview to be clarified. Field notes taken during the observations constituted the third data collection strategy.

An interpretational approach was employed to answer the research questions, while triangulation was used to consolidate the findings. Gall, Gall, and Borg (1999) defined interpretational analysis as a process which "involves a systematic set of procedures to code and classify qualitative data to ensure that the important constructs, themes, and patterns emerge" (p. 315). Applying the interpretational principles to this study, individual interviews were transcribed and coded using Saldaña's (2009) two coding cycle methods. The purpose was to identify teacher attitudes towards MT use but also their beliefs as to when it should be used in the classroom. The participants' views and perceptions on the issue, therefore, generated the codes for Research Questions 1, 2, and 4. Codes on these questions were highlighted using colour pens. Each time in the transcript a reference to one of those themes appeared, it was colour-coded as each individual colour represented a theme. Of course, during the Second Cycle Coding, these segments were further refined and subdivided. The observational protocol notes along with the field notes were also coded to provide an overview of the different classroom purposes the participants' MT use served.

As no permission was granted by the administration of the schools to record the lessons, the researchers acknowledge the challenges that constitute the practice of taking notes about language use in real-time. Acknowledging the impossibility of isolating every single MT utterance, the study did not focus on measuring and categorising the teachers' MT utterances. Instead, the observations provided an overview of MT usage employed by the participants in their lessons that later formed the basis of the third part of the individual interviews. Based on Neokleous' (2017) model, the teachers' utterances in Norwegian recorded by the researchers in the observation sessions were classified as speech acts as they "were categorised in accordance with the action each fulfilled" (p. 319). The teachers' speech acts were "based on their illocutionary nature and therefore terminated... whenever the speaker's intent behind the utterance was accomplished" (p. 320). As a result, the length of the speech acts that emerged ranged from single words to sentences that were more complex. 
To comply with the ethical issues raised by the decision to conduct classroom observations, it is necessary to specify several aspects of the study further. As no observations were made of the students and no sensitive information that makes identification of the participants possible was collected, it was not necessary to seek approval from the Norwegian Centre for Research Data for the classroom observations. The actual focus of the study was not disclosed to the teachers until the individual interviews so as not to influence data collected. Teachers were initially told that the focus of the study was on classroom interaction. During the interviews, when the actual focus was revealed, participants were given the option to withdraw from the study. None of them chose to do so.

\section{Findings}

The sections that follow outline the complexities and contradictions in the teachers' attitudes towards the use of the MT in the EFL classroom that the study unravelled.

\subsection{Teacher beliefs about MT use}

The four participants discussed several benefits of integrating the MT in their lessons. More specifically, they emphasized the usefulness of resorting to the MT to ensure that their students understood information and instructions relating to in-class tasks and activities. Anita (7), for instance, stated that "I use Norwegian mainly to make sure that they [the students] have understood what they are going to do". Furthermore, the teachers also saw the MT as useful to promoting understanding of topics they perceived the students to find challenging, such as grammar. Torill (9) commented that "sometimes when I teach grammar, which is quite important, I might do [it] in Norwegian”. Resorting to the MT thus became a way for these teachers to ensure student understanding and promote their learning.

At the same time, however, Anne (8), Berit (10), and Torill (9) articulated a critique against the practice of integrating the MT. They regarded it as incorrect, bordering on inappropriate practice. Torill (9), for instance, argued that "you should use English as much as possible". Similarly, Berit (10) stated that "the idea is that I have to use English [all the time]". During their interviews, the three teachers identified frequent use of the MT as a potential problem that could culminate in non-desirable teaching situations. Anne (8) stated 
that "[If I rely on the use of Norwegian], I feel that I do not do my job properly". Furthermore, both Anne (8) and Torill (9) justified their focus on avoiding the MT by emphasizing that it was important for their students' language learning that they, as teachers, resorted to the TL. Anne (8), for example, stated that she avoided using Norwegian in the classroom because "if I use it a lot, they [the students] would not speak English (...) and they would not practice". Similarly, Torill (9) stated, "If I talk more Norwegian, they might think that it would be OK to use more Norwegian and maybe not push themselves that much". It is thus clear that to Anne (8) and Torill (9), minimizing MT and maximizing TL usage was a conscious strategy to promote students' learning.

\subsection{Teachers' self-reporting of their MT use}

There seemed to be a discrepancy, however, between what some of the teachers reported to be the classroom reality and the reality we encountered during the observations. Arva and Medgyes (2000) defined this as the difference between the "stated" and the "actual" behaviour (p. 358). Berit (10) and Anita (7), for instance, underreported the presence of the MT in their classrooms. As Anita (7) insisted: "I use English every time, but I alternate a bit now and then. I aim to have 50-50 in both languages as a minimum". Her reporting, however, was in stark contrast to her classroom practice during which we pinpointed strong reliance on the MT. In fact, throughout the entirety of her lessons, she heavily depended on using Norwegian for various classroom purposes. Her approach could also be interpreted as an all-MT one as she mostly used complete sentences in Norwegian either to provide instructions or to answer students' questions. Instances of TL use essentially included sentences that were part of the grammatical tasks from the coursebook, and occasionally, phrases such as "good" were used to praise students for their correct answers.

Similarly, Anne (8) and Torill (9) reported in their interviews their preference to rely on Norwegian exclusively when explaining grammar or when the students encountered difficulties. As Torrill (9) elaborated: "I think it's important to spoon-feed them English, especially when they are at a higher level...This is what I try to do". Anne (8) also emphasized the need to integrate English whenever the students "required more information about things we cover in grammar". Their reporting, however, did not reflect what we observed as we noticed that both teachers made frequent recourse to Norwegian in parts of 
the lesson where the emphasis was not on grammar. For instance, Torill (9) answered questions her students asked her using Norwegian even in two cases we pinpointed where the students framed their questions in English. Correspondingly, Anne (8) resorted to Norwegian to answer most of the students' questions but also to provide instructions for some of the inclass activities.

Therefore, a common thread through the four teachers' practice was the use of the MT in the classroom and the contradictions and complexities in the teachers' attitudes towards the MT which manifested itself in the admissions of guilt expressed during the interviews. The feeling of guilt was initially traceable in the four teachers' attempt to minimise their reported MT use and was further highlighted by their eager provision of a clear rationale supporting their decision to employ the MT. For instance, Anita (7) and Berit (10) justified using the MT because of the number of weak learners in their classes who needed extensive guidance. Elaborating further, Berit (10) stated that "I'd love to speak in English the whole time," but that she sometimes used Norwegian "because there are a couple of students who don't understand English that much". Anita (7) gave a similar justification for using Norwegian stressing that "I am always worried about the weakest pupils when I use English". She also emphasized that she had many recently arrived refugees in her class and that, while they could understand Norwegian, "some of them (...) have not had English before, and ... I think that [only speaking English] is a bit harsh".

\subsection{Classroom purposes of teacher MT use}

While the four teachers in their interviews cautioned that MT use could minimize the fostering of the TL, they also highlighted specific purposes for which the MT should be used to enhance TL learning. When asked when, and for what purposes, they used Norwegian in their classrooms, the participants gave four reasons: a) deepening students' TL understanding, b) allowing students to keep up with the pace of the lesson, c) helping struggling learners, and d) strengthening their own confidence.

In their interviews, they referred to using the MT primarily in an effort to deepen students' understanding of English. When teaching elements that the teachers perceived as difficult for their class, such as grammar or new vocabulary items, they felt that students understood more easily when the MT was used in the explanatory part of the lesson. For instance, Anita (7) 
and Torill (9) reported feeling that explaining grammar in the MT was essential because it fulfiled functions that the TL could not. As Anita (7) elaborated, she used Norwegian when teaching grammar "because that is such a heavy topic". Furthermore, Torill (9) and Anne (8) stated that they resorted to the MT to explain unfamiliar vocabulary. Torill (9) explained: "When I use difficult words and students look at me puzzled and I understand that they haven't understood what I said, I switch over to Norwegian and then go back". Similarly, Anne (8) explained that she employed the MT when "I know I'm using a word that is new to them that they have never heard before and I want them to expand their vocabulary". This attitude seemed to chime with the observations as in their sessions we underlined a preference for explaining grammatical concepts in the MT. This key role that the MT could play in similar classroom situations has also been highlighted in studies undertaken by Copland and Neokleous (2011) and Alshehri (2017). What could be identified as problematic with their assertions, however, was the teachers' perception of their students as a homogeneous group. The teachers seemed not to acknowledge that learners might process, comprehend, and retain grammar information differently.

Furthermore, the four teachers stated that they used Norwegian to enable students to keep up with the pace of the lesson, as its integration ensured that the students understood the content discussed in class. As Torill (9) explained: "To make sure they [the students] understand, if I see that they don't follow me, sometimes, I use Norwegian”. Similarly, Anne (8) argued that she first tried to make her students understand by rephrasing and simplifying the information, “but if I can see they don't follow me, I turn to Norwegian”. For this reason, Anita (7), Berit (10), and Torill (9) argued that they employed Norwegian to ensure that the students were able to follow information and instructions relating to in-class tasks and activities. In line with their reported classroom practice, we observed their preference for providing instructions in the MT as a considerable number of instructions took place in Norwegian in their classes. For example, referring to one of the sessions observed during which her students were writing texts on their laptops, Torill (9) elaborated that she used Norwegian to explain to her students "how to share and save a document". Using the MT in this context ensured that the session was not disrupted by technical issues and that all students could understand and thus keep up with the rest of the lesson. 
However, the use of Norwegian to give instructions and information was most prominent in Berit's (10) classes. We observed that in her classes, students relied on the provision of instructions in the MT, and in the few instances or occasions that the teacher furnished them in the TL, students asked Berit (10) to translate them into Norwegian. Most commonly, Berit (10) translated the instructions of an activity to the MT, usually without reading the original instructions in English or devoting time to encouraging the students to read the instructions by themselves. When asked, Berit (10) stated that she used Norwegian "to get ... messages across" and to make sure her students understand "how to solve tasks". Thus, it was evidenced both in the sessions observed but also in their interviews that instructions should be given using Norwegian. Interestingly, their perceptions on this matter seemed not to closely align with the English subject curriculum which, although it does not specifically instruct teachers regarding use of MT and TL, states that students should be able to follow simple instruction given in English even in grade 2. As evinced in our observations of Berit's (10) classes, teachers seemed to rely on instructions in the MT even at $10^{\text {th }}$ grade when the students have already acquired a sufficient understanding of the TL to follow simple instructions.

Teachers further incorporated the MT in their classrooms as a tool for bolstering student confidence. In particular, Berit (10), Torill (9), and Anne (8) emphasized the role the MT could play when working with struggling students in the EFL classroom, especially when it could help them feel comfortable, while at the same time boosting their confidence and motivation for language learning. Anne (8) stated that "some of my students have low selfesteem and confidence, so I know that I have to go to those students and . . . say something in Norwegian ... to make them feel comfortable". Similarly, relating to her struggling students, Berit (10) suggested that using the MT could "help them relate [what they learn] to their own language, [and then] it is easier for them to understand". Thus, the teachers felt that using the MT could promote both language fluency and understanding. Elaborating further, Berit (10), Torill (9), and Anne (8) argued that they interacted with students they perceived as struggling to make them understand that using the MT is acceptable. Anne (8) insisted that "with students with difficulties, I tell them it's OK, you don't have to use English the whole time. . . It should be OK to come to class, and not be scared". Similarly, referring to some students who "shut down" when they hear English, Torill (9) explained that "my goal is not that they 
shut down but that they try to find a way, to understand... I'm working on making them feel safe to tell, I haven't understood what you've just said”. These excerpts suggest that Berit (10), Torill (9), and Anne (8) used the MT as a strategy to revive students' confidence and their motivation for language learning. This use of the MT is mirrored in studies conducted by Ozfidan (2017) and Orland-Barak and Yinon (2005).

Interestingly, in her interview Anita (7) also admitted that she sometimes used Norwegian to improve her own confidence. She elaborated: "If I feel that I am standing there looking for a word I can't remember, I feel that I will be less stressed...if I switch to Norwegian". Torill (9) reported that not knowing the English word felt like a personal letdown. As she argued: "If I feel that I do not know what I want to say in English, then it might have an impact on my self-esteem". Similarly, Anne (8) mentioned how using Norwegian extensively in her English classes would make her feel "awkward". These statements support the findings of studies conducted by Meiring and Norman (2002) and Bateman (2008), which attributed the reluctance of the participants to conduct class in the TL to their lack of confidence in the TL.

\subsection{MT guidelines in the Norwegian curriculum}

When asked whether they believed that the Norwegian curriculum should provide clearer guidelines regarding the use of the MT in the EFL classroom, the four teachers unanimously expressed opposition to the formulation of strict guidelines. Their resistance to the creation of more detailed MT classroom practices was linked to potential problems with its universality, as certain variables (e.g., student proficiency, lesson objectives, topic) might necessitate different MT practices. Torill (9) argued that having uniform guidelines would be problematic "because each classroom is different. . . It should be up to us teachers to find the balance [between MT and TL use]". Furthermore, the teachers argued that MT use should be interpreted through the individual teacher's intuition and that such flexibility is necessary in the classroom. Elaborating further, Berit (10) identified that "you need the flexibility. . You can't control those things because students are different". The idea of flexibility was also supported by Anne (8), who stated that "I have to make my own decisions based on my students and through communicating with them". It is thus clear that the teachers opposed 
curricular guidelines which would restrict their flexibility and autonomy as decision-makers regarding MT and TL use in their classrooms.

\section{Discussion and Implications}

The data suggest that the four teachers acknowledged the potential of the MT in the monolingual classroom. This aligns with findings from earlier studies investigating teacher perspectives (al-Bataineh \& Gallagher, 2018; Carless, 2008; Copland \& Neokleous, 2011 Escobar \& Dillard-Paltrineri, 2015). Evidently, the attitudes of the four participants reflect a recent evolution in the EFL field: namely, the acceptance of the judicious use of the MT as a helpful classroom tool and resultant encouragement of teachers to adopt a flexible languaging approach (García, 2009; Lee \& Macaro, 2013; Lin \& Wu, 2015). However, feelings of guilt still plagued teachers who employed the MT in their classrooms, as the MT usage they reported in their interviews did not reflect their actual behaviour. These traces of guilt were also uncovered during the interviews as the four teachers attempted to justify the discrepancy between their professed desires and their actual practice. As it transpired, these feelings can be attributed to the teachers' lack of confidence in maintaining a class in which English is featured prominently. Consequently, the impossibility of adopting an all-English approach has led them to underreport their MT usage. Carless (2008) explained that guilt is experienced by non-native teachers as "normal" because their "mandate is to improve students' English language. . How does this occur if students are conversing in the MT?" (p. 332). This feeling manifested itself in Copland and Neokleous' (2011) and Carless' (2008) studies that identified guilt as the element that could "help [researchers] . . understand the contradictions and conflicts in the teachers' attitudes, practices, and beliefs" (p. 277).

Even after the teachers, whose lessons featured the MT prominently, openly admitted to using it, they felt the need to provide justifications of their practice. Despite acknowledging in their interviews the importance of the presence of the MT in their lessons, the general feeling that permeates in the teaching environments in favour of an all-English approach could be deemed responsible for preventing them from accurately reporting their MT usage, and from creatively exploiting the potential of the MT in the classroom. Admitting their heavy reliance on the MT could also be interpreted as an obstacle towards their 
aspiration of creating a classroom setting where the MT is used judiciously. The latter was evidenced in their interviews where the four teachers cited specific classroom purposes for which the MT should be used as it was believed to optimize the learning experience. The difficulty of abiding by the guidelines they stated could also be held responsible for the discrepancy between their stated and classroom behaviours. Cook (2001) argued that "the pressure from this mostly unacknowledged anti... [MT] attitude has prevented language teaching from looking rationally at ways in which the ... [MT] can be involved in the classroom" (p. 410). While it appears that the teachers are attempting to use the MT critically, there is a clear need for further research to support or negate their hypotheses regarding the benefits of its use. More importantly, especially with EFL classrooms in Norway becoming increasingly multilingual and multicultural, teacher-training programs need to delve deeper into the topic of MT use and translanguaging. As recent research endorses the multilingual turn and promotes the idea of judicious MT use in the classroom, introducing pre-service teachers to the notion of translanguaging would help them better understand the natural linguistic behavior of multilingual students and use the students' entire linguistic repertoires as a resource. For this to take place, teachers need to be provided with practical recommendations of translanguaging pedagogies that take advantage of the students' MTs to develop their EFL literacy but also optimize the learning environment.

Although the results of this study offer interesting insight into occasions during which teachers deem the use of the MT essential, they are not generalizable to all EFL teachers in Norway due to the small sample size and the limited number of classes observed. To generate a more adequate portrayal of MT practices and perhaps assist in the provision of clearer guidelines both in teacher training programs and in the curriculum, more extensive research on the topic is required. For this to be materialized, however, different variables should be taken into account including grade levels and student proficiency. It would be particularly interesting to explore young and adult EFL learners' attitudes towards the purposes that they feel the MT should serve in the classroom as they might be in contrast with what the teachers expressed in this study.

Future research ought also to explore what ratio would qualify as judicious MT use, as the definition of this term remains rather elusive (Lin \& Wu, 2015; Krulatz et al., 2016; Neokleous, 2017; Wang, 2019). It may be important to differentiate between judicious use 
with new language learners as opposed to intermediate or advanced language learners, and to recommend when and under what circumstances the MT ought to be used with learners at different stages of fluency. Further exploration of what judicious means in practice would assist in recommending an optimal approach to language teaching. It is therefore important that both the views of language teachers and the views of language learners be used when researchers infer best practices for MT use. Conducting individual classroom action research projects and taking into consideration the student voice would assist in-service teachers but also teacher-trainers in grasping a clearer understanding of what the students perceive as judicious MT use. Furthermore, it would also shed light on the classroom purposes for which students believed the MT should be used.

As also reflected in recent research, the acceptance of MT use would play a significant part in enhancing students' TL learning. Taking this initial step would pave the way for the evolution of practice in this field and ease the acceptance of flexible languaging approaches amongst teachers. Future research should focus on the development of teaching strategies that incorporate the students' MT and thus optimize the language learning process. For this reason, it is pertinent that classroom language use, including both the use of the MT and multilingual translanguaging approaches, is discussed in teacher training programs. Hornberger and Link (2012) argue that "developing awareness of...translanguaging...can provide teachers with a fuller understanding of the resources students bring... and help... identify ways in which to draw on these resources for successful educational experiences" ( $p$. 264). Hornberger and Link's (2012) claim is highly relevant in Norwegian settings, especially since recent research underlines the increasing linguistic diversity in classrooms in the country (Surkalovic, 2014). Because of this increasing diversity, teachers should be able to deepen students' TL knowledge through pedagogical approaches that rely on learners' bilingual or multilingual resources. Incorporating translanguaging into classroom practice would "contribute towards removing the stigma with which the MT is associated, as well as the guilt triggered by the difficulty of maintaining an all-TL environment" (Krulatz et al. 2016, p. 147). Embracing judicious MT use in the classroom would assist both teachers and students in the creation of a more productive learning environment. It is our hope that the results of this study will contribute to the alleviation of the negative attitude that surrounds MT use in Norway, an attitude our results suggest is firmly rooted in Norwegian EFL 
teachers' attitudes towards their teaching, so that language learning can become not only more inclusive and flexible but also more effective.

\section{References}

al-Bataineh, A., \& Gallagher, K. (2018). Attitudes towards translanguaging: how future teachers perceive the meshing of Arabic and English in children's storybooks. International Journal of Bilingual Education and Bilingualism. Retrieved from https://www.tandfonline.com/doi/full/10.1080/13670050.2018.1471039?casa_tok en=Nv21zI2xORoAAAAA\%3AHvJIRf5uPCok_VFVJMQWQ1mirAX3TmGR7W1E wXsLmniSkg-MTAcMQ-L_Q4V1Um9ynZw1CC7KYyw0CA

Alshehri, E. (2017). Using learners' first language in EFL classrooms. IAFOR Journal of Language Learning, 3(1), 20-33.

Aronin, L., \& Singleton, D. (2019). Introduction. In D. Singleton, \& L. Aronin (2019),Twelve lectures on multilingualism (pp. xiii-Xxvi). Bristol: Multilingual Matters.

Arva, V., \& Medgyes, P. (2000). Native and non-native teachers in the classroom. System, $28,355-372$.

Bateman, B.E. (2008). Student teachers' attitudes and beliefs about using the target language in the classroom. Foreign Language Annals, 41(1), 11-28.

Brown, A.V. (2009). Students' and teachers' perceptions of effective foreign language teaching: A comparison of ideals. The Modern Language Journal, 93, 46-60.

Burden, P. (2000). The use of the students' mother tongue in monolingual English "conversation" classes at Japanese universities. The Language Teacher, 24(6), 5-10.

Carless, D. (2008). Student use of the mother tongue in the task-based classroom. ELT Journal, 62(4), 331-338.

Chambers, F. (1991). Promoting use of the target language in the classroom. Language Learning Journal, 4(1), 27-31.

Cheng, X. (2013). Research on Chinese college English teachers' classroom code-switching: Beliefs and attitudes. Journal of Language Teaching \& Research, 4(6), n.p.

Cheung, Y. L., \& Braine, G. (2007). The attitudes of university students towards non-native speakers English teachers in Hong Kong. RELC Journal, 38(3), 257-277.

Cook, V. (2001). Using the first language in the classroom. The Canadian Modern Language Review/La Revue canadienne des langues vivantes, 57(3), 402-423.

Copland, F., \& Neokleous, G. (2011). L1 to teach L2: Complexities and contradictions. ELT Journal, 65(3), 270-280.

Creese, A., \& Blackledge, A. (2010). Translanguaging in the bilingual classroom: A pedagogy for learning and teaching? The Modern Language Journal, 94(1), 103-115.

Drew, I. (2004). Survey of English teaching in Norwegian primary schools. Unpublished manuscript, Stavanger University College, Stavanger, Norway.

Drew, I., Oostdam, R., \& van Toorenburg, H. (2007). Teachers' experiences and perceptions of primary EFL in Norway and the Netherlands: A comparative study. European Journal of Teacher Education, 30(3), 319-341.

Eikrem, B.O. (2012). "Betre å vere stor enn liten": Korleis elevane opplever engelskfaget, sett i lys av arbeidsmåtane som vert nytta. In P. Haug (Ed.), Kvalitet $i$ opplaeringa: Arbeid i grunnskulen observert og vurdert (pp. 101-121). Oslo: Det norske samlaget. 
Escobar, C. F., \& Dillard-Paltrineri, E. (2015). Professors' and students' conflicting beliefs about translanguaging in the EFL classroom: Dismantling the monolingual bias. Revista De Lenguas Modernas [Modern Languages Journal], 23, 301-328.

Flores, N., \& Aneja, G. (2017). "Why needs hiding?" Translingual (Re) orientations in TESOL teacher education. Research in the Teaching of English, 51(4), 441-463.

García, O. (2009). Education, multilingualism and translanguaging in the 21st century. In A. Mohanty, M. Panda, R. Phillipson, \& T. Skutnabb-Kangas (Eds.), Multilingual education for social justice: Globalising the local (pp. 128-145). New Delhi: Orient Blackswan.

García, O., Johnson, S., \& Seltzer, K. (2017). Translanguaging classroom: Leveraging student bilingualism for learning. Philadelphia: Carlson.

García, O., \& Kleyn, T. (2016). Translanguaging theory in education. In O. García, \& T. Kleyn (Eds.), Translanguaging with multilingual students: Learning from classroom moments (pp. 9-33). New York: Routledge.

García, O., \& Wei, L. (2014). Translanguaging: Language, bilingualism and education. London: Palgrave Macmillan.

Gall, J. P., Gall, M. D., \& Borg, W. R. (1999). Applying educational research: A practical guide. Boston: Pearson.

Halasa, N.H., \& Al-Manaseer, M. (2012). The use of the first language in second language learning reconsidered. College Student Journal, 46(1), 71-82.

Hall, G., \& Cook, G. (2012). Own-language use in language teaching and learning. Language Teaching, 45(3), 271-308.

Hornberger, N. H., \& Link, H. (2012). Translanguaging and transnational literacies in multilingual classrooms: A biliteracy lens. International Journal of Bilingual Education and Bilingualism, 15(3), 261-278.

Inbar-Lourie, O. (2010). English only? The linguistic choices of teachers of young EFL learners. International Journal of Bilingualism, 14(3), 351-367.

Kim, S. (2008). Five years of teaching English through English: Responses from teachers and prospects for learners. English Teaching, 63(1), 51-70.

Krashen, S.D. (1985). The input hypothesis: Issues and implications. New York: Longman.

Krulatz, A., Neokleous, G., \& Henningsen, F.V. (2016). Towards an understanding of target language use in the EFL classroom: A report from Norway. International Journal for $21^{\text {st }}$ Century Education, 3(Special), 137-152.

Lee, J.H., \& Macaro, E. (2013). Investigating age in the use of L1 or English-only instruction: Vocabulary acquisition by Korean EFL learners. The Modern Language Journal, 97(4), 887-901.

Lee, J. H., \& Levine, G. S. (2018). The effects of instructor language choice on second language vocabulary learning and listening comprehension. Language Teaching Research, https://doi.org/10.1177/1362168818770910

Lin, A.M.Y. \& Wu, Y. (2015). 'May I speak Cantonese?' Co-constructing a scientific proof in an EFL junior secondary science classroom. International Journal of Bilingual Education and Bilingualism 18(3), 289-305.

Liu, M., \& Jackson, J. (2008). An exploration of Chinese EFL learners' unwillingness to communicate and foreign language anxiety. The Modern Language Journal, 92(1), 71-86. 
Macaro, E. (1997). Target language, collaborative learning, and autonomy. Clevedon: Multilingual Matters.

Macaro, E. (2001). Analysing student teachers' codeswitching in foreign language classrooms: Theories and decision making. The Modern Language Journal, 85(4), 531-549.

MacDonald, C. (1993). Using the target language. Cheltenham: Mary Glasgow Publications.

Mattioli, G. (2004). On native language intrusions and making do with words: Linguistically homogenous classrooms and native language use. English Teaching Forum, 42(4), $20-25$.

Makalela, L. (2015). Moving out of linguistic boxes: The effects of translanguaging strategies for multilingual classrooms. Language and Education, 29(3), 200-217.

May, S. (2014). The multilingual turn. Oxon: Routledge.

McMillan, B.A., \& Rivers, D.J. (2011). The practice of policy: Teacher attitudes toward "English only". System, 39(2), 251-263.

Mehl, T.H. (2014). Attitudes and awareness around code switching. What are teachers' and students' attitudes towards codeswitching in the English learner classroom in Norway, and what can influence the teachers' utilization of it? (Master thesis, University of Oslo, Norway). Retrieved from http://www.duo.uio.no/handle/10852/40548

Meiring, L., \& Norman, N. (2002). Back on target: repositioning the status of target language in MFL teaching and learning. Language Learning Journal, 26(1), 27-35.

Neokleous, G. (2017). Closing the gap: Student attitudes toward first language use in monolingual EFL classrooms. TESOL Journal, 8(2), 314-341.

Neokleous, G., \& Krulatz, A. (2018). Investigation into Norwegian teachers' perspectives on the use of students' mother tongue in the EFL classroom. Journal of Linguistics and Language Teaching, 9(2), 1-28.

Norwegian Directorate for Education and Training. (2020). English subject curriculum. Retrieved from https://www.udir.no/lk20/eng01-04

Orland-Barak, L., \& Yinon, H. (2005). Different but similar: Student teachers' perspectives on the use of L1 in Arab and Jewish EFL classroom settings. Language, Culture and Curriculum, 18(1), 91-113.

Otheguy, R., García, O., \& Reid, W. (2015). Clarifying translanguaging and deconstructing named languages: A perspective from linguistics. Applied Linguistics Review, 6(3), 281-307.

Ozfidan, B. (2017). Right of knowing and using mother tongue: A mixed method study. English Language Teaching, 10(12), 15-23.

Saldaña, J. (2009). The coding manual for qualitative researchers. London: Sage.

Sampson, A. (2012). Learner code-switching versus English only. ELT Journal, 66(3), 293- 303

Shin, J. Y., Dixon, L. Q., \& Choi, Y. (2020). An updated review on use of L1 in foreign language classrooms. Journal of Multilingual and Multicultural Development, 41(5), 406-419.

Simensen, A. M. (2005). Ja, engelsk er noe vi møter som barn og det er ikke lenger et fremmedspråk. Sprogforum-tidsskrift for sprog-og kulturpaedagogik, 35, 57-61.

Surkalovic, D. (2014). Forbereder grunnskolelærerutdanningen engelsklærere for undervisning i engelsk som tredjespråk i Norge? Acta Didactica Norge, 8(2), 1-17. 


\section{Nordic Journal of Modern Language Methodology}

Tarnopolsky, O. (2000). EFL teaching and EFL teachers in the global expansion of English. Working Papers in Educational Linguistics, 16(2), 25-42.

The Curriculum Development Council (2004). English language curriculum guide. (http://www.edb.gov.hk/attachment/en/curriculum-development/kla/engedu/primary\%201_6.pdf)

Wang, D. (2019). Multilingualism and translanguaging in Chinese language classrooms. Cham: Palgrave Macmillan. 